\title{
Role of ethnicity on the association of MAPT H1 haplotypes and subhaplotypes in Parkinson's disease
}

\author{
Susan Winkler ${ }^{1,2}$, Inke R König ${ }^{3}$, Katja Lohmann-Hedrich ${ }^{1,2}$, Peter Vieregge ${ }^{4}$, \\ Vladimir Kostic ${ }^{5}$ and Christine Klein*,1,2
}

\author{
${ }^{1}$ Department of Neurology, University of Lübeck, Lübeck, Germany; ${ }^{2}$ Department of Human Genetics, University \\ of Lübeck, Lübeck, Germany; ${ }^{3}$ Institute of Medical Biometry and Statistics, University of Lübeck, Lübeck, Germany; \\ ${ }^{4}$ Department of Neurology; Hospital Lippe-Lemgo, Lemgo, Germany; ${ }^{5}$ Department of Neurology, University of Belgrade, \\ Belgrade, Serbia
}

An association of the $\mathrm{H} 1$ haplotype and subhaplotypes in the microtubule-associated protein Tau (MAPT) gene with Parkinson's disease (PD) has been reported. To further evaluate their role in PD, we genotyped a sample set of 765 cases and controls consisting of two large European subgroups of German $(n=418)$ and Serbian $(n=347)$ origin for the MAPT haplotypes $\mathrm{H} 1$ and $\mathrm{H} 2$. The $\mathrm{H} 1 / \mathrm{H} 1$ carriers were tested for three additional MAPT polymorphisms. In the Serbian sample, there was significant evidence $(P=0.0108)$ of an association of the $\mathrm{H} 1 / \mathrm{H} 1$ genotype and PD. Surprisingly, in the German sample, we did not find significant differences in genotype or haplotype frequencies between patients and controls. These results suggest that the role of $\mathrm{H} 1$ haplotypes in the etiology of PD may be ethnically dependent.

European Journal of Human Genetics (2007) 15, 1163-1168; doi:10.1038/sj.ejhg.5201901; published online 18 July 2007

Keywords: Parkinson's disease; MAPT haplotypes; ethnicity

\section{Introduction}

Although in the past decade several monogenic forms of Parkinson's disease (PD) have been identified, the cause of the disease in the majority of cases remains unknown, and a combination of (multiple) susceptibility genes and environmental factors is discussed. ${ }^{1}$ Many association studies of various polymorphisms within different candidate genes have been described, often yielding conflicting results and thus precluding definite conclusions.

A specific haplotype of the microtubule-associated protein Tau (MAPT) gene, denominated the H1 haplotype, has consistently been reported to be overrepresented in patients with progressive supranuclear palsy, a form

${ }^{*}$ Correspondence: Professor C Klein, Department of Neurology, University of Lübeck, Ratzeburger Allee 160, 23538 Lübeck, Germany.

Tel: + 49-451-2903-353; Fax: + 49-451-2903-355;

E-mail: christine.klein@neuro.uni-luebeck.de

Received 6 March 2007; revised 21 June 2007; accepted 21 June 2007; published online 18 July 2007 of atypical parkinsonism. ${ }^{2}$ Furthermore, an association with the $\mathrm{H} 1$ haplotype and idiopathic PD has also been demonstrated in most but not all studies. ${ }^{3-10}$ Interestingly, a biological effect of this haplotype was shown in two different cell lines in vitro; the $\mathrm{H} 1$ haplotype was more efficient at driving gene expression than the $\mathrm{H} 2$ haplotype, suggesting increased MAPT expression as the H1-mediated susceptibility factor in idiopathic PD. ${ }^{6}$

Recently, the H1 haplotype of the MAPT gene has been partitioned into several H1-specific subhaplotypes, six of which were exclusively found in Norwegian PD patients, but not in matched controls. ${ }^{11}$ The frequency of $\mathrm{H} 1$ subhaplotypes tagged with the specific single-nucleotide polymorphism (SNP) markers rs242562 (G/A), rs3785883 (G/A), rs2435207 (G/A) (corresponding to SNPs 1, 13, and 2 in Skipper et $a l^{11}$ (Figure 1)) was strikingly different between the 81 studied cases and 81 controls. Especially the 'A-A' haplotype, denoted by H1-SNPs 1 and 2, was the most significantly associated one with the disease. Linkage disequilibrium (LD) among these SNPs was significant in 


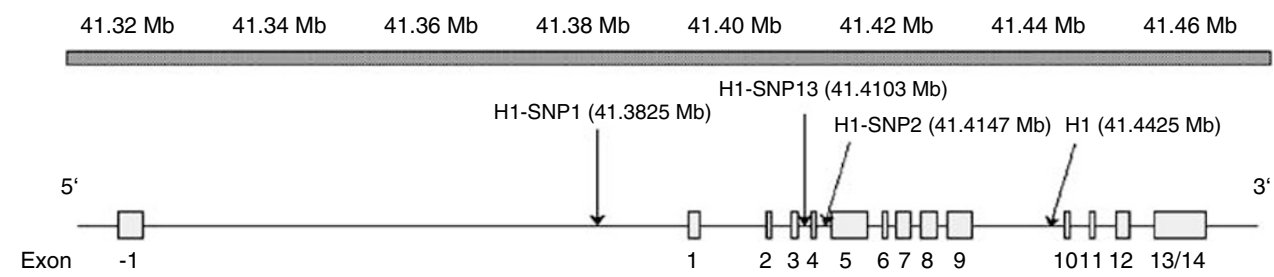

Figure 1 Diagram of the MAPT gene oriented $5^{\prime} \rightarrow 3^{\prime}$. Physical distances are given in Mb (according to www.ensembl.org, gene IDno. ENSG00000186868, May 2007); the relative position of MAPT exons are illustrated by boxes but are not drawn to scale. Positions of H1-SNPs are indicated by arrows; information on SNP position is derived from NCBI SNP database.

Table 1 PCR-conditions and sequences of H1-SNP-specific primers

\begin{tabular}{|c|c|c|}
\hline Primer & Sequences & $P C R$-conditions \\
\hline $\begin{array}{l}\mathrm{H} 1 \mathrm{~F} \\
\mathrm{H} 1 \mathrm{R}\end{array}$ & $\begin{array}{l}5^{\prime} \text {-CGG AAG ACG TTC TCA CTG ATC TG-3' } \\
5^{\prime}-\text { GGA GGA GTC TGG CTT CAG TCT CTC-3' }\end{array}$ & $95^{\circ} \mathrm{C} 5 \mathrm{~min}, 35 \times\left(95^{\circ} \mathrm{C} 30 \mathrm{~s}, 63^{\circ} \mathrm{C} 30 \mathrm{~s}, 72^{\circ} \mathrm{C} 30 \mathrm{~s}\right), 72^{\circ} \mathrm{C} 10 \mathrm{~min}$ \\
\hline $\begin{array}{l}\text { SNP1 F } \\
\text { SNP1 R }\end{array}$ & $\begin{array}{l}\text { 5'-CAG CCT TCC CTG TCC TTG ATT C-3' } \\
5^{\prime} \text {-GCC TTC CCA ACA GAG CAA CC-3' }\end{array}$ & $95^{\circ} \mathrm{C} 5 \mathrm{~min}, 35 \times\left(95^{\circ} \mathrm{C} 30 \mathrm{~s}, 58^{\circ} \mathrm{C} 30 \mathrm{~s}, 72^{\circ} \mathrm{C} 30 \mathrm{~s}\right), 72^{\circ} \mathrm{C} 10 \mathrm{~min}$ \\
\hline $\begin{array}{l}\text { SNP13 F } \\
\text { SNP13 R }\end{array}$ & $\begin{array}{l}\text { 5'-CCA TCA CCT TGT CAG AAA CTC-3' } \\
\text { 5'-AGC CAT GTG GTA GCC TCA G-3' }\end{array}$ & $95^{\circ} \mathrm{C} 5 \mathrm{~min}, 35 \times\left(95^{\circ} \mathrm{C} 30 \mathrm{~s}, 58^{\circ} \mathrm{C} 30 \mathrm{~s}, 72^{\circ} \mathrm{C} 30 \mathrm{~s}\right), 72^{\circ} \mathrm{C} 10 \mathrm{~min}$ \\
\hline $\begin{array}{l}\text { SNP13 LC } \\
\text { SNP13 FL }\end{array}$ & $\begin{array}{l}\text { 5'-CGACGCCCAGTGGTGACA-3' } \\
\text { 5'-TCCAGCCGACACTGCGCTACCC-3' }\end{array}$ & \\
\hline $\begin{array}{l}\text { SNP2 F } \\
\text { SNP2 R }\end{array}$ & $\begin{array}{l}\text { 5'-AGC AAG CTG TGT GAC CAG-3' } \\
\text { 5'-CCC ATT CTC TGA CAG ATT TG-3' }\end{array}$ & $95^{\circ} \mathrm{C} 5 \mathrm{~min}, 35 \times\left(95^{\circ} \mathrm{C} 30 \mathrm{~s}, 61^{\circ} \mathrm{C} 30 \mathrm{~s}, 72^{\circ} \mathrm{C} 30 \mathrm{~s}\right), 72^{\circ} \mathrm{C} 10 \mathrm{~min}$ \\
\hline
\end{tabular}

F, forward; R, reverse; FL, fluorescein; LC, lightcycler LC Red $640^{\circledR}$.

cases but not in controls. ${ }^{11}$ However, these findings seem to differ between ethnic groups. In a study of 133 Greek patients, the at-risk subhaplotype was the ' $\mathrm{G}-\mathrm{A}$ ' haplotype, represented by the same SNPs. ${ }^{12}$

Here, we tested a larger sample set of PD patients and matched controls from two different European populations for an association with the $\mathrm{H} 1$ haplotype and these specific SNP markers. The German subgroup represents a Northern European population and should be similar to the Norwegian group. ${ }^{11}$ To evaluate an ethnical influence on genotype frequencies, we also investigated a South-Eastern European study sample originating in Serbia that would be more similar to the Greek population. ${ }^{12}$

\section{Patients and methods Patients}

We included in our study a total of 447 cases with a diagnosis of PD $(63.3 \%$ with an age of onset lower than or equal to 50 years; $19.9 \%$ with a positive family history in at least one first- or second-degree relative; $57.9 \%$ had been screened for the presence of known mutations in Parkin, DJ-1, PINK1 and LRRK2 revealing mutations in $8.1 \%$ of them) and 318 healthy, ethnically matched controls. The majority of our study sample consisted of a group of German origin (256 PD patients: $41.6 \%$ women; mean age of onset: $46.4 \pm 12.2$ years; mean age: $55.9 \pm 12.4$ years; 162 controls: $47.5 \%$ women; mean age: $50.2 \pm 11.8$ years). The second group was of Serbian origin (191 PD patients: $39.3 \%$ women; mean age of onset: $47.7 \pm 9.7$ years; mean age: $53.5 \pm 10.3$ years; 156 controls: $55.8 \%$ women; mean age: $45.6 \pm 15.7$ years). All patients underwent a detailed neurological examination by a movement disorder specialist and symptoms were quantified by applying Part III of the UPDRS score. The diagnosis of PD was clinically established according to the UK Brain Bank diagnostic criteria. ${ }^{13}$ The German controls underwent the same neurological examination as the patients, whereas the Serbian controls had not undergone any clinical examination. Controls were ethnically matched to the patients and comprised 121 populationbased controls collected as part of a study on PD, 41 unaffected spouses of PD patients, and 156 anonymous blood donors.

\section{Genotyping}

After obtaining informed consent and approval of the study by the local Ethical Committee, DNA was extracted from venous blood samples using a standard desalting method. All probands were tested for the presence of the H1 haplotype by using specific primer pairs to amplify template DNA for the MAPT intron 9 insertion/deletion 
variant (Table 1). ${ }^{14}$ In a second step, patients and controls homozygous for the $\mathrm{H} 1$ allele (selected for the reason of phase determination) were examined for H1-SNPs 1, 13, and 2. After polymerase chain reaction (PCR) with H1-SNPspecific primers (Table 1), a restriction enzyme digest with XhoI $\left(37^{\circ} \mathrm{C}\right.$; 385-bp band for the G-allele; $287 \mathrm{bp}$ and $98 \mathrm{bp}$ for the A-allele) and $\mathrm{BclI}\left(50^{\circ} \mathrm{C}\right.$; 197-bp and 41-bp band for the G-allele; 112-bp, 85-bp and 41-bp band for the A-allele) was performed to genotype H1-SNPs 1 and 2 . To investigate the H1-SNP 13, we designed variant-specific probes (Table 1) and carried out a melting curve analysis on the LightCycler system with the melting temperature for the $\mathrm{G}$ allele of $63^{\circ} \mathrm{C}$ and for $\mathrm{A}$ of $54^{\circ} \mathrm{C}$.

\section{Statistical analyses}

A Monte-Carlo goodness-of-fit test with 10000 replications was utilized to test for possible deviations of the genotype frequencies from Hardy-Weinberg equilibrium, in each case and control group separately. Genotype frequencies for the $\mathrm{H} 1$ haplotype were compared between cases and controls by Cochrane-Armitage trend tests rendering the genotypic odds ratios (ORs) with exact 95\% confidence intervals and exact two-sided $P$-values. To account for the testing of samples from two populations, the resulting $P$-values were adjusted according to Šidak-Holm. To subsequently analyze differences in genotype frequencies at SNPs 1, 13, and 2, Cochrane-Armitage trend tests were computed exploratorily. LD was measured as $\mathrm{D}^{\prime}$ using the genassoc add-on by David Clayton for the Software Stata/ SE 9.0 (http://www-gene.cimr.cam.ac.uk/clayton/software/ stata). Frequencies of haplotypes were estimated with the Expectation-Maximization algorithm and compared between cases and controls using a score test with simulated $P$-values from $10^{6}$ replications. ${ }^{15}$

\section{Results and discussion \\ Motivation of sample assortment}

Ethnical differences among different European populations are well documented. The selection of our two ethnically different groups was based on the knowledge about ethnical differences in genomic markers. Geographic maps of gene frequencies show that Germany and Serbia are located in two different regions concerning gene distribution. ${ }^{16}$ In addition, the mutational rate of genes such as Parkin $^{17}$ and DYT $1^{18}$ has already been shown to be different in the Serbian population compared to other ethnic groups. Apart from this, the Serbian and German sample were recruited in a similar way, so that they are otherwise comparable to each other.

The overall prevalence of PD in Europe is 1.6\% for subjects 65 years of age or older and there is no large difference between different European populations. ${ }^{19}$ Therefore, one would expect that only two of our 156 Serbian controls would be false negatives, who have or will develop PD later in life. Thus, there is a possibilty to overlook an effect, but an existing one would only become stronger without these erroneously classified controls.

\section{Association with the $\mathrm{H} 1$ haplotype}

The $\mathrm{H} 1 / \mathrm{H} 2$ genotype frequencies for each of the two large different ethnic groups are shown in Table 2. The percentage of homozygous $\mathrm{H} 1 / \mathrm{H} 1$ carriers is comparable to that reported in the literature. ${ }^{5,9}$ No deviations of the genotype frequencies from Hardy-Weinberg equilibrium were detected in either cases or controls (Table 2). Considering the genotype frequencies of the $\mathrm{H} 1$ and $\mathrm{H} 2$ alleles for the whole sample set, there were no significant differences between cases and controls, independent

Table $2 \mathrm{H} 1 / \mathrm{H} 2$ genotype frequencies

\begin{tabular}{|c|c|c|c|c|c|}
\hline \multirow[b]{2}{*}{ Sample } & \multicolumn{5}{|c|}{ No. of genotypes (\%) } \\
\hline & $\mathrm{n}$ & $H 1 / H 1$ & $\mathrm{H} 1 / \mathrm{H} 2$ & $\mathrm{H} 2 / \mathrm{H} 2$ & HWE P-value \\
\hline \multicolumn{6}{|l|}{ Serbian } \\
\hline Cases & 191 & $141(73.8)$ & $42(22.0)$ & $8(4.2)$ & 0.05 \\
\hline Controls & 156 & $91(58.3)$ & $55(35.3)$ & $10(6.4)$ & 0.83 \\
\hline OR & & & 1.688 & 2.848 & \\
\hline $95 \% \mathrm{Cl}$ & & & $1.150-2.499$ & $1.322-6.246$ & \\
\hline Adjusted $P$ & & & & 0.0108 & \\
\hline \multicolumn{6}{|l|}{ German } \\
\hline Cases & 256 & $182(71.4)$ & $67(26.3)$ & $7(2.7)$ & 0.82 \\
\hline Controls & 162 & $112(69.1)$ & $41(25.3)$ & $9(5.6)$ & 0.06 \\
\hline OR & & & 1.171 & 1.370 & \\
\hline $95 \% \mathrm{Cl}$ & & & $0.805-1.697$ & $0.649-2.880$ & \\
\hline Adjusted $P$ & & & & 0.4100 & \\
\hline
\end{tabular}

Adjusted $P, P$ adjusted according to Šidak Holm for the testing of two populations; HWE, Hardy-Weinberg equilibrium, $P$-values from 10000 replications; OR, odds ratio (genotypic); $P$, two-sided exact $P$-value from Cochrane-Armitage trend test; $95 \% \mathrm{Cl}$, $95 \%$ confidence interval. Comparison of $\mathrm{H} 1 / \mathrm{H} 2$ or $\mathrm{H} 2 / \mathrm{H} 2$ vs $\mathrm{H} 1 / \mathrm{H} 1$; in Serbians $\mathrm{OR}=2.014(1.280-3.169)$, in Germans OR=1.098 $(0.715-1.686)$. 
of exclusion or inclusion of the mutation carriers (data not shown).

Comparison of the $\mathrm{H} 1 / \mathrm{H} 2$ genotype frequencies between cases and controls in our Serbian sample revealed an increased frequency of the $\mathrm{H} 1 / \mathrm{H} 1$ genotype in patients compared to controls (adjusted two-sided $P=0.0108$, Table 2). This association with PD had previously been found in several other larger studies and was also identified in two recent meta-analyses. ${ }^{5,9}$

Surprisingly, there were no significant differences in the German cohort (Table 2) despite an even larger sample size and a similar age of onset and gender distribution as in the Serbian subgroup. Notably, the power to detect an effect as previously reported ${ }^{11}$ was about $80 \%$. Although a study on Polish patients and controls, representing a neighboring European cohort, did not reveal differences in allele frequencies, either, ${ }^{8}$ our German sample seems to constitute an exception rather than the rule, especially when considering the results of a recent meta-analysis. ${ }^{9}$ The latter comprised over 4000 patients and controls from different regional cohorts that were examined in 14 independent association studies and found an exceptionally strong effect.

On the other hand, similar population-dependent differences have been well documented for mutations in monogenic PD. For example, in the LRRK2 gene, the prevalence of the p.G2019S mutation ranges from 1-7\% in PD patients of European origin to $20-40 \%$ in Ashkenazi Jews and North African Arabs with PD. ${ }^{20-22}$ Furthermore, ethnicity plays an important role also in association studies evaluating the potential impact of polymorphisms in LRRK2. ${ }^{23-26}$ Another example is a strong risk of PD which was attributed to fibroblast growth factor 20 polymorphisms in a mixed US population ${ }^{27}$ and was not confirmed in a large cohort of Finnish and Greek patients. ${ }^{28}$

\section{Association with $\mathrm{H} 1$ subhaplotypes}

We selected all homozygous carriers of the H1/H1 genotype (patients, $n=322$ (72.0\%); controls, $n=203(63.8 \%)$ of the entire sample set) for H1-SNP 1, 13, and 2 genotyping. Table 3 shows the results for the two subgroups with SNP allele frequencies which were similar as reported. ${ }^{11}$ We found no indication of differences of the genotype frequencies between cases and controls in both populations (Table 3). No deviations of the genotype frequencies from Hardy-Weinberg equilibrium were detected in either cases or controls (Table 3). Linkage disequilibrium (LD) between the three SNPs was calculated as $\mathrm{D}^{\prime}$ and found to be similar in cases and controls (Table 4). We also performed a haplotype analysis for all three SNPs. The results with overall $P$-values of $P=0.91$ in the German and $P=0.23$ in the Serbian population were in accordance with the genotype analysis and showed no significant association with PD (Table 5). However, in our large German study population, that is supposedly ethnically similar to the 
Table 4 LD for H1-SNPs

\begin{tabular}{lrccccccc}
\hline \multicolumn{1}{c}{ SNP1 vs SNP13 } & \multicolumn{3}{c}{ SNP2 vs } & SNP13 & \multicolumn{3}{c}{ SNP1 vs SNP2 } \\
Samples & $\mathrm{n}$ & $D^{\prime}$ & $R^{2}$ & $D^{\prime}$ & $R^{2}$ & $D^{\prime}$ & $R^{2}$ \\
\hline Serbian & & & & & & & \\
$\quad$ Cases & 141 & 0.34 & 0.03 & 0.37 & 0.09 & 0.30 & 0.06 \\
$\quad$ Controls & 91 & 0.13 & 0.01 & 0.44 & 0.16 & 0.45 & 0.14 \\
& & & & & & & \\
German & & & & & & & \\
$\quad$ Cases & 181 & 0.18 & 0.01 & 0.38 & 0.06 & 0.35 & 0.10 \\
$\quad$ Controls 112 & 0.22 & 0.01 & 0.40 & 0.06 & 0.37 & 0.09 \\
\hline
\end{tabular}

Linkage Disequilibrium (LD) measured by $\mathrm{D}^{\prime}$ and $R^{2}$.

Table 5 Assessment of multilocus haplotypes (H1-SNP 1-13-2-H1)

\begin{tabular}{lccccccc}
\hline & \multicolumn{3}{c}{ German } & \multicolumn{3}{c}{ Serbian } \\
Haplotype & Frequency & Score & P-value & Frequency & Score & P-value \\
\hline A-A-A-H1 & 0.0627 & -0.8121 & 0.4201 & 0.0602 & -1.8296 & 0.0711 \\
A-G-G-H1 & 0.1979 & -0.7564 & 0.4544 & 0.3822 & -1.3551 & 0.1782 \\
A-G-A-H1 & 0.1854 & -0.3055 & 0.7693 & 0.0290 & -0.2385 & 0.8230 \\
G-A-G-H1 & 0.0491 & -0.0085 & 0.9933 & 0.0745 & -0.2356 & 0.8235 \\
G-G-A-H1 & 0.0604 & 0.3396 & 0.7396 & 0.0927 & 0.5053 & 0.6176 \\
G-A-A-H1 & 0.0757 & 0.5763 & 0.5748 & 0.0368 & 0.9129 & 0.3658 \\
A-A-G-H1 & 0.0149 & 0.6186 & 0.5510 & 0.1867 & 1.0307 & 0.3051 \\
G-G-G-H1 & 0.3539 & 0.6881 & 0.5013 & 0.1379 & 1.4168 & 0.1539 \\
Overall & & 2.756 & 0.9149 & & 9.370 & 0.2265 \\
\hline
\end{tabular}

$P$-values are two-sided simulated $P$-values from $10^{6}$ simulations comparing the frequency of haplotypes between cases and controls with a total number in the German group of 293 and in the Serbian group of 232 .

previously reported Norwegian group, ${ }^{11}$ relatively narrow confidence intervals were estimated. Thus, an OR greater than approximately 2.80 for SNP1, approximately 2.43 for SNP13, and approximately 2.15 for SNP2 can be excluded with $95 \%$ probability.

To explore a potential influence of the onset age on the observed differences between the two major groups, we performed an additional subgroup analysis for the earlyonset cases (30-50 years) and detected similar differences both for $\mathrm{H} 1 / \mathrm{H} 1$ genotypes and $\mathrm{H} 1$-subhaplotypes as in the analysis of the entire sample (data not shown).

Because of the differences for gender distribution (39.3 vs $55.8 \%$ women) between the Serbian control group and the Serbian patients, we performed the analyses in this population separately for males and females (data not shown). The results of these analyses showed considerably wider confidence intervals, as expected because of the smaller sample size. However, the point estimates were very similar, and the confidence intervals largely overlapped. Specifically, for the H1/H2 haplotype, even though the differences were not significant in either males or females because of the lower power, the point estimates for the ORs, as well as the bounds for the confidence intervals, were almost identical (data not shown).
Taken together, we found a significant effect concerning $\mathrm{H} 1 / \mathrm{H} 1$ genotypes only in our Serbian group, but not in the German group. Interestingly, there was no indication for a difference in LD between H1-SNPs in cases and controls or for differences in genotypes between cases and controls for the H1-subhaplotypes as reported previously. ${ }^{11}$ It is possible that another subhaplotype is responsible for the H1-signal in the Serbian population which needs to be addressed in further studies.

Although we could not demonstrate any effect in our large German sample, our findings in the Serbian sample confirm a likely contribution of the $\mathrm{H} 1$ haplotype in the etiology of PD, as observed in previous studies. ${ }^{5,9}$ The role of $\mathrm{H} 1$ should not only be further evaluated in large case and control samples of different ethnic background, but should also be explored in more detail at the functional level to unveil the underlying pathomechanism.

\section{Acknowledgements}

This work was supported by a grant from the Deutsche Forschungsgemeinschaft, the Parkinson's Disease Foundation/National Parkinson Foundation, the Bundesministerium für Bildung und Forschung, and the University Lübeck (all to CK). CK is supported by the VolkswagenStiftung. The authors have nothing to disclose

\section{References}

1 Klein C, Schlossmacher MG: The genetics of Parkinson disease: Implications of neurological care. Nat Clin Pract Neurol 2006; 2: 136-146.

2 Pittman AM, Myers AJ, Duckworth J et al: The structure of the tau haplotype in controls and in progressive supranuclear palsy. Hum Mol Genet 2004; 13: 1267-1274.

3 Maraganore DM, Hernandez DG, Singleton AB et al: Case-control study of the extended tau gene haplotype in Parkinson's disease. Ann Neurol 2001; 50: 658-661.

4 Oliveira SA, Scott WK, Zhang F et al: Linkage disequilibrium and haplotype tagging polymorphisms in the Tau H1 haplotype. Neurogenetics 2004; 5: 147-155.

5 Healy DG, Abou-Sleiman PM, Lees AJ et al: Tau gene and Parkinson's disease: a case-control study and meta-analysis. J Neurol Neurosurg Psychiatry 2004; 75: 962-965.

6 Kwok JB, Teber ET, Loy C et al: Tau haplotypes regulate transcription and are associated with Parkinson's disease. Ann Neurol 2004; 55: 329-334.

7 de Silva R, Hardy J, Crook J et al: The tau locus is not significantly associated with pathologically confirmed sporadic Parkinson's disease. Neurosci Lett 2002; 330: 201-203.

8 Peplonska B, Zekanowski C, Religa D et al: Strong association between Saitohin gene polymorphism and tau haplotype in the Polish population. Neurosci Lett 2003; 348: 163-166.

9 Zhang J, Song Y, Chen H, Fan D: The tau gene haplotype h1 confers a susceptibility to Parkinson's disease. Eur Neurol 2005; 53 $15-21$.

10 Fung HC, Xiromerisiou G, Gibbs JR et al: Association of tau haplotype-tagging polymorphisms with Parkinson's disease in diverse ethnic Parkinson's disease cohorts. Neurodegener Dis 2006; 3: $327-333$.

11 Skipper L, Wilkes $\mathrm{K}$, Toft $\mathrm{M}$ et al: Linkage disequilibrium and association of MAPT H1 in Parkinson disease. Am J Hum Genet 2004; 75: 669-677. 
12 Fidani L, Kalinderi K, Bostantjopoulou S et al: Association of the Tau haplotype with Parkinson's disease in the Greek population. Mov Disord 2006; 21: 1036-1039.

13 Gibb WR, Lees AJ: A comparison of clinical and pathological features of young- and old-onset Parkinson's disease. Neurology 1988; 38: 1402-1406.

14 Baker M, Litvan I, Houlden $\mathrm{H}$ et al: Association of an extended haplotype in the tau gene with progressive supranuclear palsy. Hum Mol Genet 1999; 8: 711-715.

15 Schaid DJ, Rowland CM, Tines DE, Jacobson RM, Poland GA: Score tests for association between traits and haplotypes when linkage phase in ambigous. Am J Hum Genet 2002; 70: 425-434.

16 Cavalli-Sforza LL, Menozzi P, Piazza A: The History and Geography of Human Genes. Princton University Press, Chichester, West Sussex, UK, 1994.

17 Djarmati A, Hedrich K, Svetel M et al: Detection of Parkin (PARK2) and DJ1 (PARK7) mutations in early-onset Parkinson disease: Parkin mutation frequency depends on ethnic origin of patients. Hum Mutat 2004; 23: 525.

18 Major T, Svetel M, Romac S, Kostic VS: DYT mutations in a primary torsion dystonia in a Serbian population. J Neurol 2001; 248: 940-943.

19 de Rijk MC, Tzourio C, Breteler MMB et al: Prevalence of parkinsonism and Parkinson's disease in Europe: the EUROPARKINSON collaborative study. J Neurol Neurosurg Psychiatry 1997; 62: $10-15$.
20 Zabetian CP, Morino $\mathrm{H}$, Ujike $\mathrm{H}$ et al: Identification and haplotype analysis of LRRK2 G2019S in Japanese patients with Parkinson disease. Neurology 2006; 67: 697-699.

21 Lesage S, Durr A, Tazir M et al: LRRK2 G2019S as a cause of Parkinson's disease in North African Arabs. N Engl J Med 2006; 354: $422-423$.

22 Ozelius LJ, Senthil G, Saunders-Pullman R et al: LRRK2 G2019S as a cause of Parkinson's disease in Ashkenazi Jews. $N$ Engl J Med 2006; 354: 424-425.

23 Di Fonzo A, Wu-Chou YH, Lu CS et al: A common missense variant in the LRRK2 gene, Gly2385Arg, associated with Parkinson's disease risk in Taiwan. Neurogenetics 2006; 7: 133-138.

24 Tan EK, Zhao Y, Skipper L et al: The LRRK2 Gly2385Arg variant is associated with Parkinson's disease: genetic and functional evidence. Hum Genet 2007; 120: 857-863.

25 Biskup S, Mueller JC, Sharma M et al: Common variants of LRRK2 are not associated with sporadic Parkinson's disease. Ann Neurol 2005; 58: $905-908$.

26 Paisan-Ruiz C, Evans EW, Jain S et al: Testing association between LRRK2 and Parkinson's disease and investigating linkage disequilibrium. J Med Genet 2006; 43: e09.

27 van der Walt JM, Noureddine MA, Kittappa R et al: Fibroblast growth factor 20 polymorphisms and haplotypes strongly influence risk of Parkinson disease. Am J Hum Genet 2004; 74: 1121-1127.

28 Clarimon J, Xiromerisiou G, Eerola J et al: Lack of evidence for a genetic association between FGF20 and Parkinson's disease in Finnish and Greek patients. BMC Neurol 2005; 5: 11. 